\title{
As Bases de Construção do Sujeito M oderno: Posicionamento dos M ovimentos Estruturalista e Pós-estruturalista
}

Carlos Alexsandro de Carvalho Souza*

Karolyne Santana Costa*

\section{Resumo:}

A produção do conhecimento é uma das características distintivas das sociedades humanas e vem registrando mudanças decisivas nas ciências sociais. Parte dessas transformações tem como pano de fundo questionamentos epistemológicos a respeito dos principais pilares do conhecimento científico, como sua possibilidade, validade e extensão. Este trabalho se serviu da revisão bibliográfica para responder como os paradigmas estruturalistas e pós-estruturalistas contestaram a concepção kantiana de sujeito que se tornou representativa da modernidade e suas formas de produção de conhecimento. Concluiu-se que a concepção transcendental kantiana de sujeito moderno foi contestada por modelos teóricos que destacavam o papel das contingências e das estruturas, contribuindo para ampliar as possibilidades de análise dos fenômenos e para a construção de novas epistemologias.

Palavras-chave: Racionalismo transcendental. Estruturalismo. Pósestruturalismo.

* Professor da pós-graduação em Linguagens e Práticas Sociais do Instituto Federal de Alagoas (IFAL) e da pós-graduação em Docência na Educação Profissional na mesma instituição. Instituto Federal de Educação, Ciência e Tecnologia de Alagoas. Email: c.alexcarvalho@hotmail.com

** Doutoranda em Ciências Sociais. Mestre em Economia, curso de Desenvolvimento Regional e Gestão de Empreendimentos Locais e graduação em Economia todos pela Universidade Federal de Sergipe. Email: krolyne.sc@gmail.com 


\title{
The bases of Construction of the M odern Subject: Positioningof Structuralist and Post-structuralist Movements
}

\begin{abstract}
The production of knowledge is one of the distinctive features of human societies and has been recording decisive changes in social sciences. Part of these transformations has as its origin the epistemological questions about the main pillars of scientific knowledge, such as its possibility, validity and extension. This work used the literature review to answer how the structuralist and post-structuralist paradigms challenged the Kantian conception of the subject that became a representative of modernity and its forms of knowledge production. He concluded that the Kantian transcendental conception of the modern subject was challenged by theoretical models that highlight the role of contingencies and structures, contributing to expanding the possibilities of phenomenon analysis and the construction of new epistemologies.
\end{abstract} Keywords: Transcendental rationalism. Structuralism. Poststructuralism.

\section{Las Bases de Construcción del Sujeto M oderno: Posicionamiento de Los M ovimientos Estructurales y Postestructuralistas}

\section{Resumen}

La producción de conocimiento es una de las características distintivas de las sociedades humanas y ha estado registrando cambios decisivos en las ciencias sociales. Parte de estas transformaciones tiene como origen las preguntas epistemológicas sobre los principales pilares del conocimiento científico, como su posibilidad, validez y extensión. Este trabajo utilizó la revisión bibliográfica para responder cómo los paradigmas estructuralistas y postestructuralistas desafiaron la concepción kantiana del tema que se convirtió en representante de la modernidad y sus formas de producción de conocimiento. Concluyó que la 
concepción trascendental kantiana del sujeto moderno fue desafiada por modelos teóricos que resaltan el papel de las contingencias y estructuras, contribuyendo a ampliar las posibilidades de análisis de fenómenos y a la construcción de nuevas epistemologías.

Palabras clave: Racionalismo transcendental. Estructuralismo. Postestructuralismo.

A modernidade inaugura uma forma diferente de pensar e de entender o lugar ocupado pelo sujeito diante da profusão de um conjunto de valores associado às possibilidades da razão, à crença no progresso e em um conjunto de instituições que gradativamente suplantava as expressões do Antigo Regime na Europa. Ela se destaca da idade antiga em seu modo de encontrar respostas para explicar as coisas do mundo, as reflexões sobre os fenômenos da natureza, a percepção humana sobre a existência, o alcance da verdade e do conhecimento, entre outros temas que passaram a representar as dimensões do mundo moderno.

Nessa senda, o iluminismo, movimento intelectual ocorrido no século XVIII, fundamenta e guia a crença na libertação do homem de sua pequenez. Conforme expressou Kant, "Iluminismo é a saída do homem da sua menoridade de que ele próprio é culpado" (1995, p. 516). O homem deveria assumir o papel principal na construção e na narrativa de sua própria história, lidando com um conjunto de valores oriundo de um contexto que pregava a igualdade e a liberdade entre os homens e inaugurou novas perspectivas em relação à produção de conhecimento e às concepções de mundo.

O sujeito moderno passava a ser marcado por valores que poderiam ser adquiridos pelo uso da sua própria razão, cujo conhecimento não deveria ser provido por um saber baseado nas crenças religiosas ou tradições míticas. 0 ser humano, dadas as suas possibilidades de realização potencializadas pela razão, se tornaria consciente de sua capacidade autônoma para orientar 
suas ações, desviando dos condicionamentos extramundanos. Se pode imaginar que no mundo moderno o sujeito alcança um novo estatuto em relação ao conhecimento de si e do mundo.

Na obra "A crítica da Razão Pura", Immanuel Kant estabeleceu um ponto de partida crítico para o uso da razão pelo homem. A teoria do conhecimento kantiana pode ser discutida como uma tentativa de sanar as insuficiências e problemáticas que existiam nas fronteiras dos pensamentos empiristas e racionalistas enquanto correntes da filosofia moderna com as quais ela dialogava. Ela remete a uma tentativa de explicar a ciência procurando resolver lacunas existentes no acesso ao conhecimento que acabam por envolver questões entre sujeito e o objeto. Com o racionalismo transcendental kantiano se fortalecia a esperança na razão como força emancipadora que se confundia com a própria representação geral da modernidade como um projeto de sociedade.

Sua teoria do conhecimento também foi responsável por produzir bases que serviriam a futuras críticas, mesmo àquelas que estão ocasionalmente distantes na correspondência direta com seu pensamento transcendental, como, por exemplo, o estruturalismo e o pós-estruturalismo. Mas que, em certa medida, procuraram direcionar seus fundamentos teóricos na direção oposta a todas aquelas correntes que conferem o sujeito a uma posição de destaque por seus aspectos subjetivos, como a ação, a intenção, a consciência, a razão, entre outros.

O objetivo do presente trabalho é, portanto, refletir sobre a possibilidade de destacar a epistemologia crítica de Kant como referência nos termos da teorização do sujeito moderno, tido como a figura da autoconsciência, bem como quais aspectos da sua filosofia do sujeito ajudam a compreender a emergência histórica e o novo estatuto do sujeito inaugurado na modernidade. Em contraponto, procura também relatar como movimentos teóricos posteriores, a exemplo das correntes estruturalistas e 
pós-estruturalistas, se posicionam em relação ao modo como o sujeito moderno foi representado.

\section{A centralidade do sujeito como indicador da produção de conhecimento no projeto moderno}

A obra do filósofo Immanuel Kant denominada de "A Crítica da Razão Pura” é, segundo Skvirsky (2008), a mola propulsora no entendimento do processo de consolidação da modernidade, acentuadamente por suas contribuições epistemológicas como forma de estabelecer um importante marco temporal nas teorias do conhecimento que em grande medida foram fruto das mudanças mais amplas dos fundamentos históricos e filosóficos da modernidade.

Desse modo, a obra mencionada contribuiu para entender como o uso da razão se tornou central na teorização do sujeito, colocando-a como referência de um projeto de sociedade baseada nos valores sintetizados pelo Iluminismo e como proporcionadora de uma atividade radicalmente libertadora, tendo o homem como princípio de sustentação de um conjunto de expectativas do projeto moderno expresso pelo antropocentrismo. Isso possibilita uma forma de compreensão do sujeito moderno como síntese da modernidade, já que representa a centralidade da razão, a crença no progresso humano e na produção do conhecimento científico.

De forma complementar, Joas e Knöb (2017) alegam que a fase "clássica" da modernidade foi atingida por meio das obras de Rousseau e, principalmente, Kant, que representou uma nova era em que "a tese da unidade da humanidade e do universo, anteriormente justificada em termos religiosos, era substituída por outras ideias" (Joas e Knöb, 2017, p. 452). A afirmação ganha sentido quando se observa que a obra de Kant procurava responder como se dariam todos os meios ou as condições que 
possibilitaram o conhecimento humano, ou como seria possível justificar satisfatoriamente o conhecimento científico. Nesta perspectiva, o racionalismo transcendental foi influenciado pelo espírito moderno, que procurava analisar as condições que precedem a experiência, condições a priori.

Considerando a variedade de critérios sobre a delimitação temporal da modernidade, este trabalho adota a perspectiva de Peters (2000). A adoção dessa análise ajuda a compreender as influências que constituíram o sujeito moderno. Este sujeito foi objeto de várias teorizações que surgiram ao longo do período moderno e que, por sua vez, também passaram a ser alvo de críticas de diversos movimentos posteriores, como aqueles que derivavam do estruturalismo francês. Ampliando esse quadro, percebe-se que o pós-estruturalismo também deu tratamento crítico à relação sujeito-objeto.

O movimento iluminista, na medida em que saudava "a criatividade humana, a descoberta científica e a busca da excelência individual em nome do progresso humano" (Harvey, 2008, p. 23), também abraçava as inúmeras mudanças causadas por aquilo que era fugidio ao projeto. Desta forma, nota-se que o esforço se revelava em todos os aspectos gerais do espírito moderno, fosse ele vindo do advento de novas técnicas, da revolução científica, do método experimental, da crítica aos paradigmas de explicação religiosa e até mesmo do modo como, do ponto de vista social, novas composições de segmentos sociais foram responsáveis por mudanças nas sociedades europeias.

Percebe-se que a intensidade do movimento iluminista impulsionou uma mudança radical no sistema de valores dessas sociedades, estabelecendo novas práticas que passaram a ser subjacentes à própria modernidade e passaram a ser expressas nas reflexões, preocupações e na construção de abordagens epistemológicas por diversas correntes que se debruçavam sobre as 
relações entre sujeito e conhecimento. Segundo David Harvey, logo:

O desenvolvimento de formas racionais de organização social e de modos racionais de pensamento prometia a libertação das irracionalidades do mito, da religião da superstição, liberação do uso arbitrário do poder, bem como do lado sombrio na própria natureza humana (Harvey, 2008, p. 23).

Encontra-se na epistemologia kantiana a proposta de que existem certas condições a priori que levam as impressões sensíveis a se converterem em conhecimento, apesar do princípio do conhecimento residir na experiência, não se limita a ela. A reflexão kantiana sobre a forma de construção do conhecimento e a sua tentativa de estabelecer uma solução intermediária à dicotomia existente nela, em sua época, é um contributo para que se possa analisar, ainda que sucintamente, aquilo que se tornou o projeto da modernidade e toda a subjetividade do sujeito intrínseco a seu surgimento, que levou cada vez mais a ampliação dos embates teóricos daquelas vertentes filosóficas que se posicionavam em função do dualismo existente entre sujeito/objeto, sobretudo no âmbito da filosofia da ciência, desdobrando-se de modo mais amplo nas Ciências Humanas, com especial vigor no século XIX, devido às problematizações crescentes das relações entre ação e estrutura e/ou indivíduo e sociedade (Skvirsky, 2008).

Nesse panorama, progressivamente, novos caminhos guiados por esses embates teóricos apresentavam questões conflitantes entre aqueles que observavam o sujeito como o ator individual no papel de protagonista na trama social - caracterização do processo ativo do agente frente à sociedade e aqueles que viam que "as ações individuais eram, em sua totalidade, resultados da estrutura social. Em outros termos, a ação era um reflexo estrutural e, por conta disso, o indivíduo tornava-se passivo frente à sociedade" (Bender e Coelho, 2018, p. 62). 


\section{0 reconhecimento do sujeito moderno a partir do pensamento crítico kantiano}

No que concerne às principais problemáticas sobre as possibilidades de produção do conhecimento, Kant é um divisor de águas, pois sua filosofia pode ser reconhecida pelo seu criticismo que é sua dimensão mais fundamental. Por estar concentrado ao que pareciam equívocos conceituais das teorias de sua época, procurou apresentar uma crítica sobre o valor do conhecimento humano. 0 filósofo almejava entender aquilo que legitima o conhecimento e o que pode ser fundamentalmente conhecido (Bazarian, 1988). Segundo Da Silveira (2002), a epistemologia de Kant partiu, em certa medida, da constatação que nem o racionalismo, nem o empirismo eram capazes de explicar o conhecimento satisfatoriamente.

Kant procurou criar seu próprio sistema que era composto de conceitos do pensamento mais gerais ou categorias lógicas, conforme analisou Bazarian (1988), para ele o autor sustentava que "o conhecimento não é a conformidade da imagem ou ideia com a coisa, nem o reflexo do objeto na consciência do sujeito cognoscente, mas uma criação ou construção do objeto pelo sujeito" (Idem, p. 78). Esse conhecimento é construído a partir de um sujeito que acessa o mundo e assim passa a emitir seus juízos sintéticos, esta capacidade fundamental racional (a priori) leva ao conhecimento que guia ao entendimento da verdade.

Logo, se antes admitia-se que o conhecimento era regulado pelo objeto, na abordagem da filosofia transcendental "a própria experiência é um modo de conhecimento que requer entendimento" (Kant apud Da Silveira, 2002, p. 36). E "a razão impõe aos objetos conceitos a priori", partindo do pressuposto que a faculdade de intuição no sujeito regula o objeto dos sentidos (Da Silveira, 2002, p. 36). Prontamente, o que Kant parece propor é que de fato o conhecimento requer a cooperação entre instituições sensíveis e conceitos, ou seja, embora nenhum conhe- 
cimento chegue a mente sem que passe pelos sentidos, há todo um processo racional de depurar e filtrar os conteúdos da intuição, como as categorias, os conceitos, que são de natureza $a$ priori, considerados por Kant como juízos.

Dúvida não há de que todo o nosso conhecimento principia pela experiência. Sem dúvida, que outro motivo poderia despertar e pôr em ação a nossa capacidade de conhecer senão as coisas que afetam os sentidos e que, de um lado, movimentam nossa faculdade intelectual e levam-na a compará-las, ligá-las ou separá-las, transformando então a matéria bruta das impressões sensíveis num conhecimento que se denomina experiência? Dessa forma, na ordem do tempo, nenhum conhecimento precede em nós a experiência, e é com esta que todo o conhecimento se principia (Kant, 2005, p. 44).

A citação destacada chama atenção para o conhecimento puro $a$ priori, que não depende totalmente da experiência, mas que com ela se relacionava, mostrando a existência de uma lógica relacional entre a razão teórica e a prática. Este conhecimento deveria ser construído a partir do sujeito que possui uma capacidade fundamentalmente racional, que guia seu conhecimento no entendimento da verdade, as estruturas estão dentro do homem a priori - as quais o guia na busca pelo conhecimento puro.

Foi a perspectiva sobre o uso da razão como estruturadora na ordenação do conhecimento de Kant que serviu como inauguradora de uma concepção de sujeito como um elemento ativo do processo de conhecimento, e a razão, por sua vez, como a emancipadora do sujeito sensível, em que tempo e espaço se comportavam como formas a priori $^{1}$ da sua própria sensibilidade e existiam apenas na mente deste sujeito. Essas conclusões evidenciam a distância existente entre o racionalismo transcendental e o empirismo clássico, bem como do próprio racionalismo clássico da metafísica.

1 Proposto como algo que independe dos sentidos. 
O criticismo kantiano se configurou como inspiração para vários teóricos que conduziram a tendência filosófica para solidificar uma filosofia moderna que ansiava "a necessidade de investigar o homem conjuntamente à sua investigação do real" (Skvirsky, 2008, p. 16). Segundo Peters (2000), com a agenda kantiana se tornou comum que as crenças tradicionais fossem submetidas à operação da crítica, que deveria ser precursora do conhecimento. Mas como na agenda filosófica nada é facilmente esgotável, a epistemologia kantiana que influenciou outras filosofias do sujeito também remete ao surgimento de movimentos que avaliam de forma oposta esta visão do sujeito autoconsciente, autodeterminado e livre das influências estruturantes. Sobre esse ponto de vista é que será analisado o estruturalismo francês e o pós-estruturalismo como movimentos que se posicionaram em oposição ao lugar de destaque dado ao sujeito moderno.

\section{A descentralização do papel dado ao sujeito moderno no estruturalismo e no pós-estruturalismo}

O estruturalismo e o pós-estruturalismos são notoriamente contramovimentos teóricos que surgem no século XX dentro de um cenário filosófico dominante existente na vida intelectual da França, aproximadamente na metade deste século (Joas e Knobl, 2017). 0 estruturalismo pode ser caracterizado por apresentar um entendimento específico na ideia de "estrutura" que busca na análise coordenada coesão e significado no comportamento humano e no funcionamento de sua mente. Autores como Saussure, Roman Jakobson, Lévi-Strauss, Lacan, Althusser são referências teóricas desse movimento. Em sequência, o pós-estruturalista se destacou pela forma como atacou o próprio estruturalismo, a partir de uma crítica que o ataca desde o seu interior, revendo os limites do conhecimento estruturalista, criticando o excesso de cientificismo pregado e, ainda, contesta como muitos textos estruturalistas pregavam 
em demasia um descentramento da subjetividade que acabou por causar uma noção tão centrada da importância da estrutura que não sobrava nada do sujeito. Contudo, esse movimento também adota uma postura antagônica a respeito de todo protagonismo dado ao sujeito moderno, quando contestam sua autoconsciência, cuja base, conforme pontuamos, foi construída sob a influência de fundamentos do pensamento kantiano. Alguns dos seus representantes são Jacques Derrida, Jean-François Lyotard, Deleuze, entre outros.

Iniciando pelo entendimento do estruturalismo, o francês, especificamente, garante a extensão sobre o entendimento, ainda que sintético, das características comuns a este movimento em geral. 0 caso francês foi dado no período entre guerras na França, através da intensificação de novas formas de pensamento, que recepcionaram de forma diferente o pensamento alemão, as releituras em grande escala de ícones como Hegel, Marx, Freud e a revisão teórica de pensadores da fenomenologia como Husserl e Heidegger (Joas e Knoblz, 2017). As transformações do século XX também podem ser consideradas importantes fatores que exerceram influências naquele ambiente, elas se apresentavam como consequências de eventos a exemplo das "duas guerras mundiais, da II revolução industrial, as descobertas da física quântica, entre outros contextos e mostram a alta dinamicidade do tecido social e a necessidade de compreensão que ali foi criada" (Bender e Coelho, 2018, p. 61).

Nesse cenário, é possível perceber o estruturalismo francês como indicador de mudanças no universo intelectual da França na virada para o século XX e que segue até seu ápice nos anos 1950 e 1960, com reflexos que podem ser notados tanto na filosofia, na sociologia, na psicologia, na antropologia, na psicanálise, entre outras áreas, que resultou em novas abordagens e elos intelectuais contrários ao exagerado subjetivismo dominante nas ciências. Com áreas que passaram a ser premiadas com formas estruturais de rever o conhecimento, logo: 
A psicanálise acompanhou o surgimento de Jacques Lacan (1901-1981) e seus seguidores, que leram a teoria freudiana de forma particularmente estruturalista; na filosofia, na sociologia e nas ciências políticas, teóricos como Louis Althusser (1918-1990) e Nicos Poulantzas (1936-1979) começaram a reinterpretar a obra de Marx, expurgando todos os elementos considerados não científicos [...] Roland Barthes (1915-1980) tornou-se o maior e mais sensível teórico estruturalista da cultura, analisando cultura de massa na França (Joas e Knoblz, 2017, p. 384).

Os esforços teóricos desse movimento se concentravam em propor um novo método objetivo de caráter puramente científico para alcançar o conhecimento - tal como foi feito anteriormente pelo funcionalismo de Durkheim que já havia atingido um estatuto próximo do que se pode considerar um esforço para a construção de um caráter efetivamente científico para ciências humanas - objetivando dar às mudanças geradas por dinâmicas sociais uma concepção global da realidade.

Muitas vezes, porém, encontrar uma única característica exata sobre o modo como o conhecimento era pensado no estruturalismo, mesmo o francês ${ }^{2}$, é tido frequentemente como algo complexo e refratário a delimitações mais precisas. Seguindo o que pensa Piaget (1979), as estruturas invocadas pela corrente estruturalista se revestiram de formas e sentidos diversos, em diferentes campos de conhecimento, nos quais dificilmente encontraremos um denominador comum.

Por isso, a noção dos caminhos que levam à formação do conhecimento no estruturalismo deve ser observada como uma história complexa e difusa, sendo extremamente comprometedor

2 Não é possível falar em homogeneidade entre as teorias estruturalista da contemporaneidade, mas elas podem, segundo Piaget (1979), ser sintetizadas por seu ideal positivo que recobre a ideia de estrutura e por sua crítica, que as acompanham em oposição às tendência reinantes em diferentes disciplina do período. 
tentar entendê-la somente como "uma unidade de pensamento ou mesmo uma circunscrição bem delimitada de premissas" (Sales, 2013, p. 165). Mas, a critério de entendimento e cientes da não homogeneidade na proposta estruturalista, é possível observar que existem muitas sínteses de caráter estrutural que se reconhecem na existência deste ideal usual de inteligibilidade, que tentam investigar nas discussões a queixa estruturalista sobre "todas as formas de recursos ao sujeito humano em geral" (Piaget, 1979, p. 8). A mesma opinião é compartilhada por Reali e Antiseri, para os quais:

O estruturalismo filosófico é um leque de propostas díspares que encontram, contudo sua unidade em um protesto comum contra a exaltação do eu e a glorificação do finalismo de uma história humana feita ou, de qualquer forma, guiada ou co-criada pelo homem e por seu esforço (Reali e Antiseri, 2006, p. 82).

Por esse motivo, Sales (2003) afirma que a origem do estruturalismo Francês, em sua concepção moderna e na medida em que provoca repercussão em toda ciência humana, está conectada à linguística estrutural de Ferdinand Saussure e Roman Jakobson. Havia a pretensão nesse movimento francês de emitir novos métodos e trazer explicações a todos aqueles que não se sentiam satisfeitos com as respostas dadas pelas ideologias até então dominantes nas ciências humanas que dedicavam ao sujeito um estágio central na sua própria história (Peters, 2000). Esta inquietação foi tratada por Lévi-Strauss em uma crítica direcionada da seguinte forma:

0 estruturalismo reintegra o homem na natureza e, se permite fazer abstração do sujeito - insuportável enfant gaté que tem ocupado tempo demais na cena filosófica e impedindo qualquer reflexão séria [...] Os que criticam em nome de valores sagrados da pessoa humana, se fossem coerentes consigo mesmos, argumentariam de outro modo. Deveriam 
dizer: se a finalidade postulada por todos os seus procedimentos não está nem na consciência nem no sujeito, aquém dos quais você procura situá-la, onde estaria, a não ser fora deles? (Lévi-Strauss, 2011, p. 663).

Essas palavras compartilhadas por Lévi-Strauss a respeito do papel do estruturalismo e a crítica àqueles críticos do movimento fortalecem a proposta aqui retratada, que considera o método estruturalista como um freio às ideias constituídas da modernidade que encontram respaldo em um sujeito totalmente livre de quaisquer influências. A posição de Lévi-Strauss também realça uma ruptura epistemológica ocorrida nos anos 1950 e 1960, quando há um recrudescimento do interesse pelas estruturas inconscientes e a influência exercida por elas na capacidade de escolha do sujeito.

Ainda sobre o foco do estruturalismo antropológico de Lévi-Strauss, ele pode ser encarado como "a encarnação da crença na perenidade da natureza humana", segundo Piaget (1979, p. 86). 0 modelo dedutivo construído por Lévi-Strauss era, segundo as observações daquele autor, de caráter exemplar para as ciências humanas empíricas. Nele se nota que o modelo dedutivo poderia ser visto como a dimensão estrutural, cujos aspectos ultrapassam a individualização dos contextos. Pimenta (2013) também destaca o feito de Lévi-Strauss na obra "O pensamento Selvagem" que, entre outras coisas, é a sua apresentação sobre a tentativa de investigar a forma de constituição do "mundo da natureza" ou "experiência".

É possível observar que a noção de 'estrutura' na obra de Lévi-Strauss pode se comportar como a definição que propõe Piaget $(1979$, p. 8) para o termo, segundo o qual em uma primeira análise o termo 'estrutura' trata de "um sistema de transformações que comporta leis enquanto sistema". Este sistema que no olhar de Bender e Coelho (2018) objetiva, por meio da construção destas leis e a partir de generalizações, obter uma explicação total dos fenômenos. 
A abordagem de Lévi-Strauss se distancia daquilo que Kant propôs ao sustentar em sua epistemologia que a concepção de que qualquer fenômeno é constituída a partir das sensações, ordenadas por formas a priori da sensibilidade - espaço e tempo - e que resultam nas percepções. É, no entanto, a razão que se aplica às formas a priori do entendimento, desta forma alcançando os fenômenos mais puros: os noumena. Assim, os objetos eram dados ao sujeito pela sensibilidade e "pensados através de conceitos e princípios no entendimento" (Da Silveira, 2002, p. 40), ou seja, as duas faculdades cognitivas são indispensáveis ao conhecimento. 0 fenômeno em Kant é a perspectiva da realidade, pois a experiência não permite atingir a verdade "universal", que só se chega através da razão pura.

Dito isso, se pode pensar que o estruturalismo de Lévi-Strauss tem postura epistemológica totalmente diferente da kantiana ao propor uma metodologia que remete à destituição "do sujeito transcendental de suas prerrogativas", conforme trata Pimenta (2013, p. 313), ligando-o a um contexto e justificando seu comportamento dentro de uma lógica societal e estruturalmente condicionada. Ao apresentar o seu método ele cumpre com o objetivo de mostrar questões que levam teoricamente ao entendimento da dissolução da subjetividade humana na totalidade que a razão projetou no mundo, revertendo em sua teoria a ideia de primazia que era subjacente ao sujeito. Desta forma, o sujeito, no estruturalismo, poderia ser visto como um objeto sob o efeito das ideias de estrutura, ainda que subconscientemente. Suas ações na sociedade eram limitadas por diversos fatores que estão além da sua subjetividade.

As influências do estruturalismo "clássico" ou "tradicional", conforme denominou Joas e Knöbl (2017, p. 384), a respeito da produção acadêmica, acabaram por ser reduzidas a partir do final da década de 1970. Nesta insígnia, se tem a ascensão de um movimento que se tornou conhecido como pós-estruturalismo. Este termo é assim denominado pois alguns dos principais no- 
mes que povoam esse cenário vieram da tradição Estruturalista, ainda que, em alguma medida, afastem-se dela. As concepções pós-estruturalistas providenciaram uma nova roupagem teórica. A crítica feita ao papel dado às estruturas e à ideia que muitas vezes nos escritos estruturalistas havia tanto de estrutura que não sobrava nada do sujeito é uma das questões fundamentais dessa concepção, no entanto, nesta revisão nos interessa principalmente compreender como, dadas as considerações necessárias, o posicionamento desta corrente quanto ao papel do sujeito é também antagônico àquelas que, em alguma medida, foram influenciadas pelos adeptos ao pensamento kantiano.

Williams (2012) apresenta o pós-estruturalismo como um movimento filosófico que se comporta de forma divergente ao tradicionalismo "das ciências e dos valores morais estabelecidos" (Idem, p. 10) e que de certa forma dissemina influência para um leque de áreas de conhecimento ampliado, incluindo a sociologia. Segundo o autor, o âmago comum ao movimento são os limites do conhecimento. Peters (2000) argumenta que o pós-estruturalismo bebe nas releituras de estruturalistas da primeira fase, a exemplo de Lévi-Strauss. No entanto, o movimento pode ser encarado como uma forma de filosofar que não possui uma unidade comum, e, por isto, pode ser o próprio termo questionado em essência, opinião compartilhada por Terry Eagleton:

Em lugar de ser uma estrutura bem definida, claramente demarcada, encerrando unidades simétricas de significantes e significados, ela passa a assemelhar-se muito mais a uma teia que se estende sem limites, onde há um intercâmbio e circulação constante de elementos, onde nenhum dos elementos é definível de maneira absoluta e onde tudo está relacionado com tudo (Eagleton, 2006, p. 194-5).

A despeito disso, Williams (2012) destaca o movimento como uma prática de diversos trabalhos que pretendiam realizar uma crítica ao estruturalismo a partir do seu interior, revendo posi- 
ções sobre os limites do conhecimento estruturalista para o qual as mudanças só ocorrem quando há alterações nas estruturas observadas. Segundo Giacoia (2006), os pós-estruturalistas eram "confluentes a que respeita a certo conjunto de temas, como o privilégio da diferença sobre a identidade, o caráter plural do pensamento, a ruptura com os grandes empreendimentos de sistematização e totalização do conhecimento, o descentramento da subjetividade" (Idem, p. 143), entre outros pontos.

Os pós-estruturalistas também estão empenhados em realizar um ataque aos pressupostos pretensamente universalistas da racionalidade, da individualidade e da autonomia do sujeito que foi fortalecida, conforme mencionado, nas constituições teóricas que partiram do criticismo kantiano. Sua crítica é voltada à exclusão do outro que está intrínseco a este processo universalista de autoafirmação do sujeito, por isto os pós-estruturalistas negam a autoconsciência a substituindo por uma "constituição discursiva do eu - sua corporeidade, sua temporalidade e sua finitude, suas energias inconscientes, e libidinais - e a localização e histórica e cultural do sujeito" (Peters, 2000, p. 36).

Peters mostra que o pós-estruturalismo "inaugura e registra a recepção francesa de Nietzsche” (2000, p. 29-31) e também a interpretação de Martin Heidegger sobre ele, além das releituras de Nietzsche feitas por Deleuze, Derrida, Foucault, Klossowski e Koffman, entre as décadas de 1960, 1970 e 1980. Para ele, os pós-estruturalistas continuavam a questionar as diversas construções filosóficas do sujeito, entre elas a cartesiano-kantiana, que tendiam a colocar o sujeito como centro de toda análise e teoria, sustentando, de forma variada, "a compreensão estruturalista do sujeito".

O livro "Nietzsche e a Filosofia", escrito por Gilles Deleuze, é um dos momentos inaugurais do pós-estruturalismo e estabelece um ponto de virada da filosofia francesa. Nessas condições, é válido introduzir a seguinte passagem: "a razão é apenas um conceito, e um conceito bem pobre para definir o plano e os mo- 
vimentos infinitos que o percorrem" (Deleuze, 2004, p. 60), esta tiragem mostra a crítica do autor feita ao privilégio dado à pretensão de se obter a verdade pelo uso da razão que se vê no pensamento kantiano. Observe essa passagem em Kant na qual ele nota que a razão não deveria se apresentar como um aluno que se deixa guiar por tudo que é dito por seu professor, mas na qualidade "de juiz nomeado que obriga as testemunhas a responder as perguntas que lhe propõe" (2005, p. 50).

Williams (2012, p. 86) propõe que Deleuze trata estrutura como a razão que conduz a transformação da coisa. Estrutura não se define pela repetição da unidade, mas como uma condição necessária à sua transformação. É a estrutura que dá o limite do conhecimento de determinada coisa, ela age como uma parte viva, que lhe dá a intensidade necessária do que pode vir a ser uma mudança. A visão de múltiplas estruturas e discursos heterogêneos estão presentes na obra de Deleuze e procuram romper com a dicotomia existente na concepção do sujeito moderno e aquele puramente estrutural.

O processo de identificação tem alta relevância, assim como foi visto em Deleuze, a estrutura não determina a ação do sujeito. 0 pós-estruturalismo não concede privilégio ao sujeito moderno, mas há também uma desconstrução da estrutura. Assim, Newman (2005) defende que se no estruturalismo o sujeito é algo unificado marcado por sua identidade fixa e estável que lhe é acomodada pela estrutura a-histórica, para os pós-estruturalistas ele não é unicamente uma estrutura, mas um acontecimento e, como tal, não pode deixar de pertencer a uma ordem histórica. Para De Souza (2013), o sujeito se comporta como uma incompletude que é constituída e delimitada a caráter da contingência social e pela sua indecibilidade.

Dessa forma, os pós-estruturalistas rejeitam o essencialismo de qualquer parte, por isto o sujeito de seus trabalhos aparece na maior parte das vezes como resultado de um movimento de 
produção e efeito, bem diferente daquele sujeito completamente autônomo, contida na perspectiva da noção ou filosofia do sujeito constituída a partir das premissas kantianas, que foram a base para o sujeito moderno.

Williams mostra que "o pós-estruturalismo deve muito ao método kantiano da filosofia transcendental” (2012, p. 28), pois ao ponto que as ideias do pensamento kantiano vão exatamente em direção oposta ao que eles desejam combater, existem pontos que levam o "pós- estruturalismo a apresentar limites que podem ser vistos como as condições transcendentais para o âmago" (Idem, p. 28).

Em resumo o que o trabalho aborda é similar à visão geral traçada por Hall. Na sua obra "A identidade cultural na pós-modernidade" ele traça um panorama de como foi importante o trabalho de alguns autores das correntes Estruturalista e Pós-Estruturalista para propor teorias que procuravam descentralizar a ideia de sujeito moderno. 0 autor enfatiza que esse movimento contribuiu para construir uma visão que "nós não somos, em nenhum sentido, os 'autores' das afirmações que fazemos ou dos significados que expressamos na língua” (Hall, 1992, p. 40), ou seja, que reproduzimos "sistemas de significados de nossa cultura”, sendo a língua um sistema social e não individual, boa parte deste pressuposto está associada às influências saussurianas e à linguística estrutural dela derivada, e, portanto, se afasta significativamente da concepção kantiana de sujeito.

No pós-estruturalismo, Hall (1992) também traça um panorama que reforça essa questão. Ele propõe que alguns autores, ao revisarem os conteúdos estruturalistas, acabaram por ser influenciados pela "virada-linguística de Saussure" (Idem, p. 41) que, em geral, propunha que "nossas afirmações são baseadas em proposições e premissas das quais nós não temos consciência, mas que são, por assim dizer, conduzidas na corrente sanguínea de nossa língua" (Idem, 1992, p. 41). Esta passagem, por exemplo, pode ser vista no trabalho de Derrida (2001), o qual supôs a 
existência de que há sempre uma lacuna na ação postulada por um antes e um depois e nela cabe interferência de outros, que fogem ao nosso controle.

Faz-se oportuno registrar que não é pretensão do trabalho esgotar o debate sobre todas as formas que caracterizam essas correntes de pensamento aqui tratadas, já que toda exposição feita neste trabalho é uma síntese com o objetivo de destacar o modo como essas correntes alteraram a forma de encarar o sujeito moderno, tomando, em grande medida, mesmo diante das profundas críticas tecidas, a modelação do entendimento do sujeito moderno a partir da herança kantiana.

\section{Considerações Finais}

O artigo explorou, por meio de revisão bibliográfica, como a razão e o modelo de indivíduo foram pensados na modernidade, partindo do pressuposto que ao observar estes cenários é possível perceber que usualmente muitas teorias epistemológicas passadas foram influenciadas a entender o conhecimento a partir do sujeito autoconsciente e livre. Essas influências, dadas as considerações cabíveis, advêm de alguns conceitos fundamentais do pensamento transcendental kantiano. É explorado como a epistemologia kantiana foi basilar nas influências na constituição do sujeito moderno tido como aquele que deveria adquirir seus valores pelo uso da própria razão e cujo conhecimento não deveria ser baseado em crenças religiosas ou tradições míticas, o que o tornaria consciente suficiente de si mesmo e do mundo, livre dos condicionamentos extramundanos.

No segundo momento, o artigo mostrou como os movimentos do estruturalismo e do pós-estruturalismo são antagônicos à concepção desse sujeito, pois em seus escritos os autores procuram destacar que há limites diante dos quais se depara o sujeito que o impede de ser guiado inteiramente por um processo racional com suas ações. Essas correntes trouxeram novos elementos às 
análises, como a ideia de estrutura no estruturalismo. E toda a questão que envolve o ceticismo ao projeto científico das ciências humanas que traz o pós-estruturalismo.

Por fim, o artigo explorou como com a construção desses novos métodos de análise e formas de pensar propostos por essas correntes citadas se construíram fortes rupturas sobre as ideias majoritárias da modernidade quanto à construção da verdade, sobre o papel do sujeito moderno, das formas de acesso ao conhecimento que foram diretamente influenciadas por uma agenda teórica que encontrou na epistemologia de Kant fundamentos necessários aos seus desenvolvimentos.

\section{Ref erências}

BAZARIAN, Jacob. 0 problema da verdade: teoria do conhecimento. São Paulo: Alfa-Omega, 1988.

BENDER, Mateus; COELHO, Gabriel Bandeira. Anthony Giddens E Pierre Bourdieu: É Possível Falar Em Pós-estruturalismo? Interfaces Científicas-Humanas e Sociais, v.7, n. 1. p. 59-70, 2018.

DA SILVEIRA, Fernando Lang. A teoria do conhecimento de Kant: o idealismo transcendental. Caderno brasileiro de ensino de Física, Florianópolis, v.19, número especial, p. 28-51, jun. 2002.

DELEUZE, G. 0 que é a filosofia? Trad. Bento Prado Jr. e Alberto Alonso Muñoz. Rio de Janeiro: 34, 2004.

DERRIDA, Jacques. Writing and difference. London: Routledge, 2001.

DE SOUZA, Eloisio Moulin, Susane Petinelli Souza, and Alfredo Rodrigues Leite da Silva. 0 pós-estruturalismo e os estudos críticos de gestão: da busca pela emancipação à constituição do sujeito. RAC-Revista de Administração Contemporânea, 17, no. 2 (2013).

EAGLETON, Terry. Teoria da Literatura: Uma Introdução. São Paulo: Martins Fontes, 2006.

JOAS, Hans; KNÖBL, Wolfgang. Teoria Social: Vinte lições introdutórias. Tradução de Raquel Weiss. Rio de Janeiro: Vozes, 2017. 
GIACOIA, Oswaldo. Pequeno Dicionário de Filosofia Contemporânea. São Paulo: Publifolha, 2006.

HALL, Stuart. A identidade cultural na pós-modernidade. Porto Alegre: DP\&A, 1992.

HAMM, Christian. Kant. In: Os Filósofos Clássicos da Filosofia, de Kant a Popper. Vol. II. Rio de Janeiro: Vozes, 2008.

HARVEY, David. Condição pós-moderna. Tradução Adail Ubirajara Sobral. 17 a edição. São Paulo: Loyola, 2008.

LÉVI-STRAUSS, C. Mito e significado. Lisboa: Edições 70, 1987.

2011.

Mitológicas: 0 homem nu. São Paulo, Cosac Naify, volume IV,

KANT, Immanuel. Resposta à pergunta o que é Iluminismo. In: KANT, Immanuel. A Paz Perpétua e outros Opúsculos. São Paulo: Edições 70, 1995.

Crítica da razão pura. São Paulo: Martin Claret, 2005.

NEWMAN, S. Power and politics in post structuralist thought: new theories of the political. London: Routledge, 2005.

PIAGET, Jean. O Estruturalismo. Tradução Moacir Renato. 3a edição. Rio de Janeiro: Difel, 1979.

PIMENTA, Pedro Paulo. Kant no pensamento selvagem de Lévi-Strauss. Revista de Antropologia, p.: 291-320. Universidade de São Paulo, São Paulo, 2013.

PETERS, Michael. Pós-estruturalismo e filosofia da diferença: uma introdução. Belo Horizonte: Autêntica, 2000.

REALI, Giovanni; ANTISERI, Dario. História da Filosofia: de Freud à atualidade. São Paulo: Paulus, 2006. v. 7.

SALES, Léa Silveira. Estruturalismo - história, definições e problemas. Revista de Ciências Humanas 33: 159-188, 2003.

SIMONIS, Yvan. A Paixão do Incesto: Introdução ao Estruturalismo. Tradução de Manuel de Castro. Rio de Janeiro: Moraes, 1968.

SKVIRSKY, Alexandre A. Pereira. Dogmatismo e Ceticismo na Filosofia Crítica de Kant. Dissertação (Mestrado em Filosofia). Pontifícia Universidade Católica do Rio de Janeiro. Rio de Janeiro, 2008.

WILLIAMS, James. Pós-estruturalismo. Petrópolis: Vozes Limitada, 2012. 